\title{
POTRET CAMBRIDGE ADVANCED (CHEMISTRY AS AND A LEVEL) DI SEKOLAH MUTIARA HARAPAN RIAU TAHUN AJARAN 2015/2016
}

\author{
Renny Kurnia Sari, Yeva Olensia \\ Universitas Islam Negeri Raden Fatah Palembang \\ E-mail: rennykurniasari_uin@radenfatah.ac.id
}

\begin{abstract}
Abstrak: Sekolah Mutiara Harapan (SMH) adalah sekolah non-profit yang didirikan dan didanai oleh PT. Riau Andalan Pulp and Paper Pangkalan Kerinci Riau, yang mengakomodasi kebutuhan pendidikan anakanak karyawan. Komunitas SMH terdiri dari orang Indonesia dan expatriat, oleh karena itu kurikulum di SMH terdiri dari kurikulum nasional dan internasional.Senior High /SH-SMH menggunakan Cambridge curriculum dan Kurikulum Tingkat Satuan Pendidikan (KTSP). Kurikulum internasional Cambridge, menitikberatkan kemampuan siswa dalam pemahaman, pengetahuan, keterampilan dan berpikir kritis. Pengumpulan data penelitian menggunakan dokumentasi, observasi, dan wawancara. Metode analisis data menggunakan teknik triangulasi. Penelitian ini berlokasi di SMH Riau, sedangkan subjek dalam penelitian ini adalah guru kimia dan siswa XI dan XII IPA tahun ajaran 2015/2016. Hasil penelitian menunjukkan bahwa minat siswa SMH cukup tinggi untuk mengikuti kelas chemistry As/A level, namun hanya sedikit siswa yang mengikuti Cambridge International Examination. Hal ini disebabkan oleh beberapa faktor diantaranya: biaya, minat, kemampuan, dan faktor eksternal. Chemistry As/A level benar-benar mempersiapkan siswa untuk melanjutkan ke tingkat perguruan tinggi, dimana dapat dilihat dari segi tujuan, isi, metode, dan evaluasi.
\end{abstract}

Kata Kunci: Guru, siswa, CambridgeAdvanced, Chemistry AS and A Level, Sekolah Mutiara Harapan Riau

\section{PENDAHULUAN}

Sekolah Mutiara Harapan (SMH) adalah sekolah non-profit yang didirikan dan didanai oleh PT. Riau Andalan Pulp and Paper Pangkalan Kerinci Riau, yang mengakomodasi kebutuhan pendidikan anak-anak karyawan. Komunitas SMH terdiri dari orang Indonesia dan expatriat, oleh karena itu kurikulum di SMH terdiri dari kurikulum internasional dan kurikulum nasional. Menurut Undang-Undang Sistem Pendidikan Nasional (UUSPN), Nomor 20 tahun 2003 dalam Kompri (2014), kurikulum adalah seperangkat rencana pengaturan mengenai tujuan, isi dan bahan pelajaran serta cara yang digunakan sebagai pedoman penyelenggaraan kegiatan pembelajaran untuk mencapai tujuan pendidikan tertentu. Untuk Primary Years Programme (PYP) atau tingkat sekolah dasar SMH menggunakan sistem Internasional Baccaulaureate (IB) sejak tahun 2009. Sekaligus menjadikan SMH sebagai salah satu IB world school di Indonesia dan satu-satunya $I B$ world school di Riau. Sedangkan untuk middle school yakni tingkat junior high dan senior high SMH telah terakreditasi oleh Cambridge International Examination (CIE) sejak tahun 2013 dimana siswa-siswa telah mengikuti Cambridge secondary 1, secondary 2, and cambridge advance. Selain itu SMH juga sudah terakreditasi A secara nasional dari Dinas Pendidikan dan Kebudayaan RI. SMH menggunakan kurikulum nasional yakni KTSP untuk tahun ajaran 2015/2016. Senior high-Sekolah mutiara harapan (SH-SMH) mengunakan Cambridge selain KTSP.

Lebih dari 9000 sekolah dari 160 negara menjadi bagian dari Cambridge learning community. Cambridge curriculum tidak hanya mengembangkan konten tetapi juga skill. Cambridge mendorong siswa untuk:

- Percaya diri dalam bekerja dengan informasi dan gagasan mereka sendiri dan gagasan orang lain

- Bertanggungjawab atas diri mereka sendiri, responsif dan menghormati orang lain

- Reflektif sebagai peserta didik, mengembangkan kemampuan untuk belajar 
- Inovatif, penuh tantangan untuk masa depan

- Terlibat secara intelektual dan sosial, siap membuat perbedaan

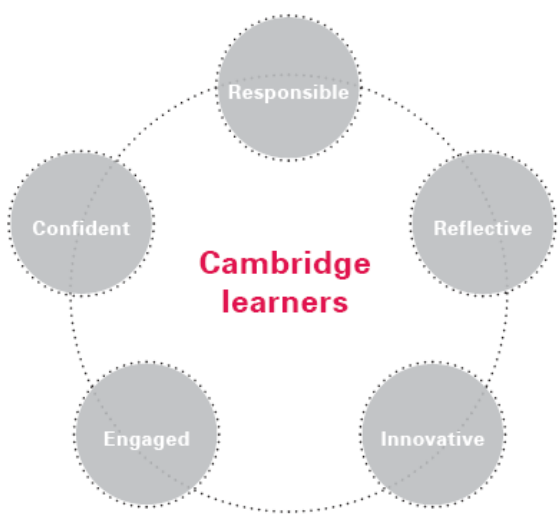

Gambar 1. Cambridge Learner

Berangkat dari sini SMH memiliki motto diantaranya menjadikan siswa-siswa

1. internationally minded

2. responsible

3. life long learners.

Cambridge programme diperuntukkan bagi siswa dengan rentang usia 5 - 19 tahun dan tersusun atas 4 program pilihan, yaitu : Cambridge Primary untuk usia 5 - 11 tahun (dengan assessmen Cambridge Primary, Cambridge Primary Checkpoint, dan ICT Starters); Cambridge Secondary 1 untuk usia 11- 14 tahun (dengan assessmen Cambridge Secondary 1, Secondary 1 Checkpoint dan ICT Starters); Cambridge Secondary 2 untuk usia 14-16 tahun (dengan assessmen Cambridge IGCSE, O Level dan ICE); dan Cambridge Advanced untuk usia 16 - 19 tahun (dengan assessmen Cambridge International A dan AS level, Pre- $U$ dan AICE). Gambar Cambridge programme disajikan dalam Gambar 2.Jenjang yang setara dengan SMA kelas XI dan XII di SMH adalah As/A level.

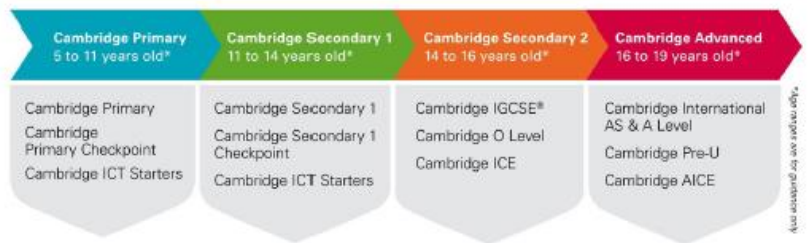

Gambar 2. CambridgeProgramme untuk setiap rentang umur

Cambridge Advanced biasanya diperuntukan bagi siswa yang membutuhkan studi lanjut untuk mempersiapkan diri di jenjang pendidikan tinggi atau universitas. Program Cambridge advance yang diikuti SMH adalah Cambridge International AS/A Level yang baru diperuntukkan untuk empat mata pelajaran yakni mathematics, biology, physics dan chemistry. Tahun ajaran 2015/2016 merupakan tahun pertama bagi SMH khusus untuk examination $A S$ dan A level karena siswa kelas XII merupakan gelombang pertama di SMH pada tahun ajaran 2015/2016. Cambridge International AS and A Levels menyiapkan siswa dengan baik untuk memasuki jenjang universitas karena mereka telah mempelajari materi secara detail dan mendalam. 
Makalah ini dimaksudkan untuk membahas potret Chemistry AS and A Level di Sekolah Mutiara Harapan Riau Tahun Ajaran 2015/2016. Adapun tujuan penulisan makalah ini diantaranya:

1. Memberikan informasi kepada pembaca tentang Cambridge Advanced (Chemistry AS and A Level) di SMH Riau Tahun Ajaran 2015/2016

2. Mengajak pembaca untuk mengamati Cambridge Advanced (Chemistry AS and A Level) sebagai bahan pertimbangan dalam memilih program kurikulum di sekolah

3. Menjelaskan kepada pembaca tentang kelebihan dan kekurangan Cambridge Advanced (Chemistry AS and A Level)

\section{PEMBAHASAN}

Terdapat tiga pilihan tipe assessment untuk cambridge international As/A level seperti yang disajikan dalam Gambar 3 .

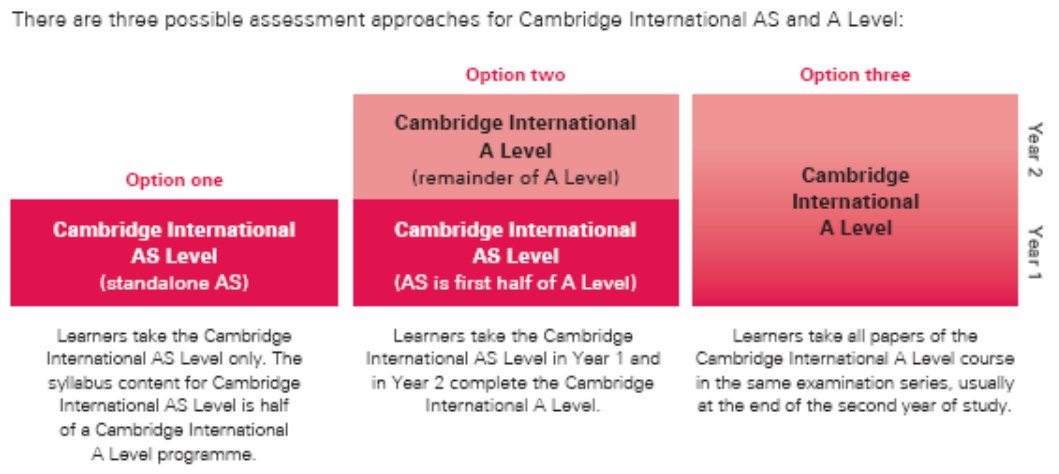

Gambar 3. Tiga Kemungkinan Assessment untuk Cambridge International As and A level

Dari tiga kemungkinan pilihan asesmen Cambridge International As and A level pada Gambar 3, Sekolah Mutiara Harapan mengambil pilihan yang kedua dimana As level untuk kelas XI dan A level untuk kelas XII. Dari total 25 siswa kelas XI IPA di sekolah mutiara harapan 13 orang diantaranya memilih untuk mengambil kelas chemistry $A S$ dan 9 orang chemistry A level dari total 19 orang siswa kelas XII IPA. Dengan demikian total siswa yang mengikuti kelas chemistry Cambridge adalah 22 orang.

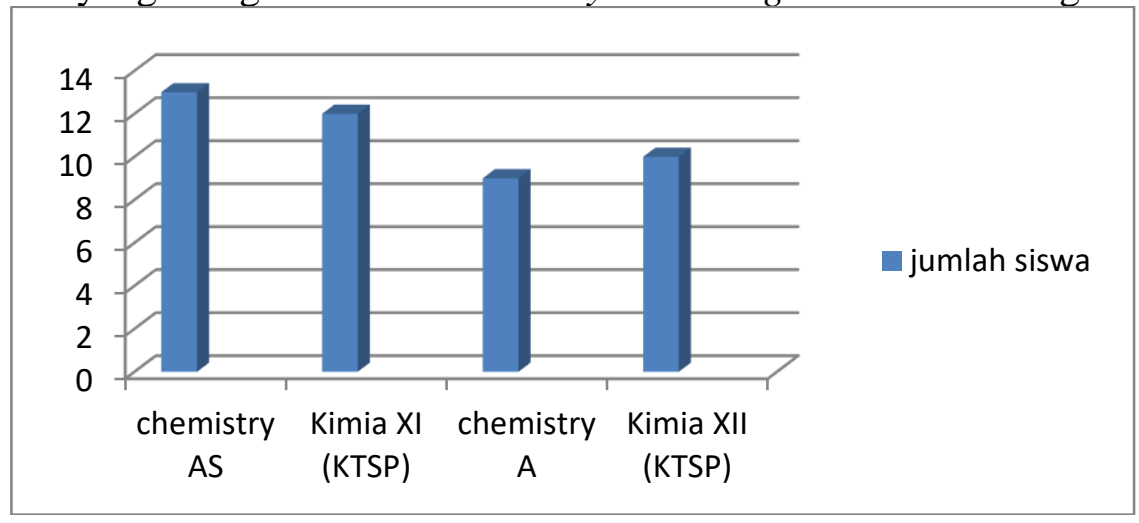

Gambar 4.Penyebaran siswa tahun ajaran 2015/2016

Dari grafik di atas terlihat bahwa minat siswa SMH cukup tinggi untuk mengikuti kelas chemisty As/A. Lebih banyak siswa di kelas chemistry As jika dibandingkan kimia XI sedangkan ketika di grade XII lebih banyak siswa yang mengambil kimia KTSP jika 
dibandingkan chemistry A. Dari grafik ini memperlihatkan bahwa minat siswa ketika sudah di grade XII terhadap kelas chemistry (Cambridge curriculum) lebih rendah. Dari hasil wawancara siswa kelas XII tahun ajaran 2015/2016, mereka memilih bertahan untuk tetap mengikuti kelas chemistry $A$ disebabkan karena mereka pada grade sebelumnya memang sudah mengikuti kelas Cambridge. Terlihat dari data siswa yang memang sebelumnya berasal dari SMH yang memang sudah mengikuti IB, Cambridge secondary 1 dan Cambridge secondary 2.

Dari total 22 orang siswa yang mengikuti kelas chemistry AS dan A level yang mengikuti ujian AS/A level hanya 4 orang yang terdiri dari 3 orang peserta $A S$ level dan 1 orang A level.

\begin{tabular}{lcccc}
\multicolumn{1}{r}{ Subject } & \multicolumn{3}{c}{ Grade } & Total \\
\cline { 2 - 4 } & 10 & 11 & 12 & \\
\hline ESL & 10 & 11 & & 7 \\
Combined Sc & 7 & & 15 \\
Mathematics & 15 & & 6 \\
Bus Studies & 6 & 6 & & 6 \\
Biology-AS & & 3 & & 3 \\
Chemistry-AS & & 4 & & 4 \\
Physics-AS & & 5 & & 5 \\
Math-AS & & & 1 & 0 \\
Biology-A & & & 4 & 1 \\
Chemistry-A & & & 4 & 4 \\
Physics-A & & & 4 \\
Math-A & & & & \\
\hline
\end{tabular}

Tabel 1. Penyebaran siswa pada kelas Cambridge berbagi subjek di SH-SMH tahun 2015/2016

Untuk As level, chemistry memiliki jumlah peminat paling sedikit, dan menempati urutan kedua terbawah untuk $A$ level setelah biology. Sedikitnya jumlah siswa yang mengikuti CIE chemistry As/A disebebkan karena beberapa faktor:

1. Biaya

Sebagaimana diketahui bahwa mahalnya biaya untuk mengikuti ujian As/A level menjadi salah satu penyebab tidak ikutnya siswa dalam ujian ini. Untuk SMH meskipun sudah ada subsidi bagi anak-anak karyawan untuk mengeyam pendidikan, namun belum ada subsidi untuk biaya tes As dan A level. Subsidi hanya diperuntukkan bagi pembayaran school fee dan beasiswa untuk siswa yang mendapat A* pada CIE.

2. Minat

Beberapa siswa meskipun mengikuti kelas Chemistry As/A level namun tidak memiliki minat untuk mengikuti ujian $A S / A$ level karena mereka tidak merasakan manfaat mengikuti tes ini jika nanti tetap kuliah di dalam negeri.

3. Kemampuan

Selain itu kesulitan yang dialami siswa adalah berbedanya istilah-istilah kimia dalam bahasa Indonesia dan bahasa Inggris dan juga adanya pebedaan satuan dalam kurikulum Cambridge dan kurikulum nasional. Sebagai contoh satuan konsentrasi yang sering digunakan dalam kurikulum nasional adalah $\mathrm{M}$ sedangkan dalam chemistry Cambridge adalah mol dm${ }^{-3}$. Satuan suhu yang biasanya adalah dalam ${ }^{0} \mathrm{C}$, sedangkan dalam Cambridge adalah $\mathrm{K}$, dan masih banyak perbedaan-perbadaan lainnya yang membuat siswa bingung dan kesulitan.

4. Eksternal 
Banyak siswa yang mengeluhkan sulitnya materi chemistry As/A level jika dibandingkan dengan 3 mata pelajaran serumpun seperti: biologi, fisika dan matematika. Hal ini di latar belakangi oleh perbedaan pengalaman guru yang mengajar dimana untuk pengajar biology dan mathematics adalah guru expat, sedangkan kimia dan fisika adalah guru nasional. Data rinci dapat dilihat pada Tabel 2. Penulis sendiri sebagai guru chemistry merasakan belum cukup pengalaman dan pelatihan dalam Cambridge. Oleh karena itu untuk chemistry dan physics As/A level mendapatkan dosen tamu 2 kali dalam satu bulan. Selain itu untuk chemistry bahasa pengantar masih menggunakan bahasa Indonesia. Tidak sepeti di kelas mathematics, biology (full English) dan physics (Bahasa dan English). Beberapa siswa mengeluhkan kurang memahami pelajaran jika dibawakan dalam bahasa Indonesia jika dibandingkan dengan bahasa Inggris.

\begin{tabular}{|c|c|c|c|c|}
\hline Subjek & Pendidikan & Pengalaman Mengajar & $\begin{array}{c}\text { Pengalaman } \\
\text { Training } \\
\text { Cambridge }\end{array}$ & Keahlian \\
\hline Mathematics & $\begin{array}{l}\text { Northland } \\
\text { Internasional } \\
\text { University } \\
\text { Bachelor of Science, } \\
\text { Secondary Education } \\
\text { International Baptist } \\
\frac{\text { College }}{\text { Master of Education, }} \\
\text { Philosophy of } \\
\text { Education } \\
\underline{\text { Virginia Beach }} \\
\underline{\text { Theological }} \\
\text { Seminary } \\
\text { Master of Divinity - } \\
\text { MDiv }\end{array}$ & $\begin{array}{l}\text { 1. Head of Math Department } \\
\text { Sekolah Mutiara Harapan } \\
\text { September } 2012 \text { - Saat ini ( } 4 \\
\text { tahun } 10 \text { bulan) } \\
\text { 2. Science Teacher } \\
\text { Sekolah Pelita Harapan } \\
\text { Agustus } 2009 \text { - Juni } 2012 \text { ( } 2 \\
\text { tahun } 11 \text { bulan) } \\
\text { 3. Math/Science Teacher } \\
\text { Harvest Christian Academy } \\
\text { Agustus } 2003 \text { - Mei } 2009 \text { (5 } \\
\text { tahun } 10 \text { bulan) } \\
\text { 4. Math Teacher } \\
\text { Tabernacle Baptist Academy } \\
\text { Agustus } 2000 \text { - Juni } 2003 \text { (2 } \\
\text { tahun } 11 \text { bulan) } \\
\text { 5. Math Teacher } \\
\text { Tri City Christian Academy } \\
\text { Agustus } 1998 \text { - Juni } 2000 \text { (1 } \\
\text { tahun } 11 \text { bulan) } \\
\text { 6. Math/Science Teacher } \\
\text { La Mesa Christian School } \\
\text { Agustus } 1995 \text { - Juni } 1997 \text { (1 } \\
\text { tahun } 11 \text { bulan) }\end{array}$ & 6 & $\begin{array}{ll}\text { - } & \text { Curriculum } \\
\text { development } \\
\text { Classroom } \\
\text { - Lesson } \\
\text { planning } \\
\text { Tutoring } \\
\text { - Classroom } \\
\text { management } \\
\text { - Educational } \\
\text { technology } \\
\text { - Educational } \\
\text { leadership } \\
\text { - Differentiated } \\
\text { instruction } \\
\text { - Teaching } \\
\text { - Teacher } \\
\text { training }\end{array}$ \\
\hline Biology & $\frac{\text { Phyliphine }}{\text { Physics }}$ & Biology teacher & 8 & $\begin{array}{l}\text { Cambridge } \\
\text { Coordinator } \\
\text { Teaching }\end{array}$ \\
\hline Physics & $\begin{array}{l}\text { Universitas Andalas } \\
\text { Fisika } \\
\text { Universitas Negeri } \\
\text { Padang } \\
\text { Akta IV }\end{array}$ & $\begin{array}{l}\text { Guru komputer sekolah } \\
\text { mutiara harapan } \\
\text { Guru fisika sekolah mutiara } \\
\text { harapan }\end{array}$ & 1 & \\
\hline Chemistry & $\begin{array}{l}\text { Universitas Negeri } \\
\text { Padang } \\
\text { Pendidikan Kimia } \\
\text { Universitas } \\
\text { Pendidikan Indonesia }\end{array}$ & - & 1 & \\
\hline
\end{tabular}


Siswa SMH yang mengambil kelas chemistry As/A level sebagian besar merupakan siswa yang juga berasal dari SMH (baik SD maupun SMP). kebanyakan dari mereka adalah siswa yang sebelumnya sudah mengikuti kelas Cambridge/IB pada jenjang sebelumnya. Meskipun sebagian kecil berasal dari sekolah dengan kurikulum nasional, dari hasil pengamatan guru di kelas ketika pembelajaran siswa yang berasal dari sekolah nasional tidak mengalami kesulitan yang berarti dalam pembelajaran. Hal ini dikarenakan siswa yang diterima di SH-SMH sudah melewati serangkaian tes yang ketat. Namun mereka cenderung memiliki minat yang rendah untuk ikut CIE As/A level. Hal ini dikarenakan beberapa faktor seperti: biaya, minat, kemampuan dan faktor eksternal. Sedangkan siswa yang sebelumnya berasal dari komunitas SMH memiliki minat yang cukup besar untuk kuliah di luar negeri sehingga juga mengakibatkan mereka mengikuti CIE As/A level, selain disebabkan oleh faktor lainnya seperti kemampuan mereka yang lebih bagus, kemampuan dari segi finansial dan dorongan orang tua.

Chemistry AS and A Level memiliki kekurangan dan kelebihan jika dilihat dari hasil observasi dan wawancara pada siswa dan guru. Siswa dari kelas Cambridge memiliki kemampuan lebih mudah memahami soal UN dibandingkan dengan siswa kelas nasional hal ini dapat terlihat dari hasil try out UN/ hasil UN siswa SMH. Hal ini dikarenakan siswa sudah terbiasa dengan soal yang jauh lebih rumit yang memerlukan analisis, evaluasi maupun paractical skillnyang bahkan tidak ada dalam evaluasi KTSP. Siswa Cambridge juga memiliki motivasi yang lebih tinggi untuk melanjutkan kuliah di luar negeri dan sudah memiliki pemahaman mengenai materi yang nanti akan disajikan dibangku kuliah karena materi-materi kurikulum Cambridge memang diseting untuk mempersiapkan siswa dalam melanjutkan studi di perguruan tinggi. Namun yang menjadikan siswa kurang meminati kelas Cambridge maupun Cambridge international examination As/A level cehemistry diantaranya adalah biaya buku yang jauh lebih mahal sepuluh kali lipat harga buku nasional, guru tidak merupakan guru expat.

\section{Tinjauan Tujuan, isi, metode dan evluasi Cambridge dan KTSP}

1. Tujuan Cambridge Advanced dan KTSP

Cambridge Advanced bertujuan untuk menyeimbangkan pengetahuan, pemahaman, dan skill sehingga siswa menjadi pembelajar yang efektif dan memiliki fondasi yang kuat untuk melanjutkan pendidikan. Sedangkan dalam KTSP secara umum yakni memandirikan dan memberdayakan satuan pendidikan dengan pemberian hak otonomi pada lembaga pendidikan dalam pengambilan keputusan. Tidak ada program khusus dalam KTSP yang khusus untuk mempersiapkan siswa ke jenjang perguruan tinggi.

2. Analisis komparasi isi Cambridge advanced (chemistry As and A level) dan kimia kelas XI dan XII Sma KTSP di SMH Riau tahun ajaran 2015/2016

\begin{tabular}{|c|c|c|c|c|c|}
\hline No & Topic & AS level & $\begin{array}{c}\text { XI } \\
\text { KTSP }\end{array}$ & A Level & $\underset{\text { KTSP }}{\text { XII }}$ \\
\hline 1 & Atoms, molecules and stoichiometry & $\sqrt{ }$ & & & \\
\hline 2 & Atomic structure & $\sqrt{ }$ & & $\sqrt{ }$ & \\
\hline 3 & Chemical bonding & $\sqrt{ }$ & & & \\
\hline
\end{tabular}


States of matter

Chemical energetics

Electrochemistry

Equilibria

Reaction kinetics

The Periodic Table: chemical periodicity

Group 2

Group 17

12 An introduction to the chemistry of transition elements

13 Nitrogen and sulfur

14 An introduction to organic chemistry

15 Hydrocarbons

16 Halogen derivatives

17 Hydroxy compounds

18 Carbonyl compounds

19 Carboxylic acids and derivatives

20 Nitrogen compounds

21 Polymerisation

22 Analytical techniques

23 Organic synthesis

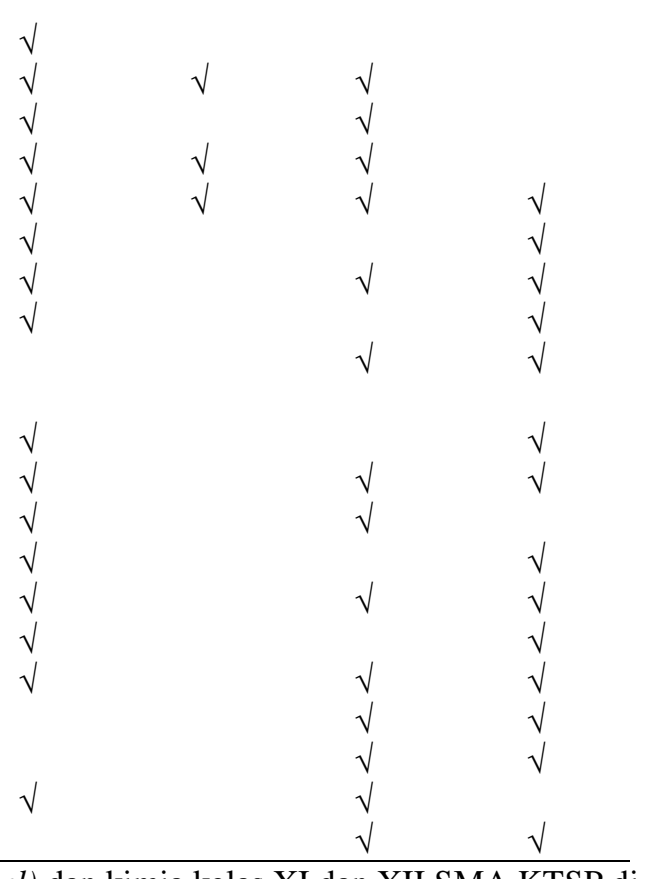

Tabel 3. Isi cambridge advanced (chemistry As and A level) dan kimia kelas XI dan XII SMA KTSP di SMH Riau tahun ajaran 2015/2016

Materi koloid yang di pelajari di kelas XI KTSP, dan sifat koligatif larutan di kelas XII tidak terdapat dalam chemistryAs/A. Selain itu satates of matter dan analytical technique yang terdapat pada Cambridge tidak terdapat pada KTSP. Meskipun pada umumnya banyak topik pelajaran chemistry Cambridge juga terdapat dalam KTSP, namun chemistry Cambridge memiliki indikator pencapaian pembelajaran yang berbeda dengan KTSP. Jika dalam KTSP lebih mengutamakan rumus, perhitungan. Dalam chemistry Cambridge lebih mengutamakan pemahaman konsep yang bahkan beberapa konsep merupakan materi yang justru dipelajari di bangku kuliah. Sebagai contoh topikreaction kinetics. Dalam KTSP biasanya mempelajari tentang laju reaksi. Jika dalam KTSP kita lebih cenderung untuk mendorong siswa untuk menghitung laju reaksi maka dalam kurikukum Cambridge bahkan terdapat tentang boltzman distribution yang justru dipelajari pada mata kuliah kimia fisika/kinetika di bangku kuliah.

3. Analisis komparasi metode cambridgeadvanced (chemistry As and A level) dan kimia kelas XI dan XII SMA KTSP di SMHRiau tahun ajaran 2015/2016

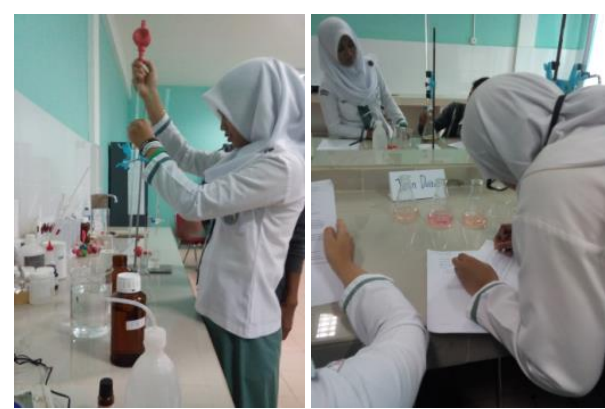

Gambar 5. Pembelajaran Chemistry As Level 


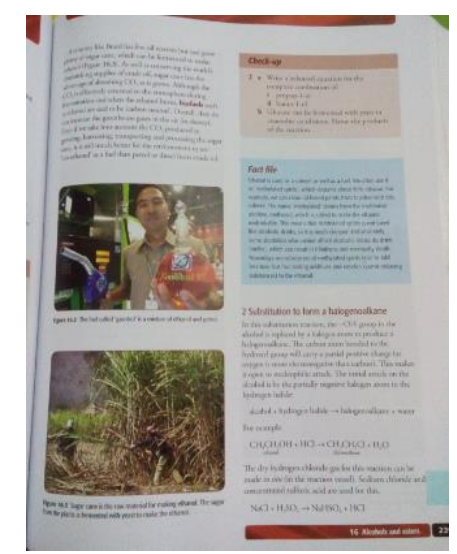

Gambar 6. Chemistry As/A Level Coursebook

Metode pembelajaran pada umumnya sama, baik untuk chemistry As/A maupun kimia XI/XII. Pembelajaran biasanya diawali dengan apersepsi, penyampaian materi oleh guru, diskusi kelas,latihan soal, dan penguatan.Dengan alokasi waktu pembelajaran yang sama yakni 6x45 menit perminggu. Dimana satu kali tatap muka adalah masing-masing 2 jam pelajaran. yang berarti dalam satu minggu terdapat 3 kali tatap muka. Yang terlihat jelas perbedaan adalah bagi guru chemistry As/A lebih mudah, terarah, dan simple dalam melaksanakan evalusi pembelajaran karena CIE sudah menyediakan secara lengkap worksheet, test yourself langsung dengan mark schemes. Begitu juga dengan pelaksanaan praktikum yang sudah dilengkapai dengan practical skills booklet yang dilengkapi dengan safety, teachers note, dan cara pembuatan larutan yang dibutuhkan secara lengkap jika dibandingkan dengan KTSP.

4. Analisis Komparasi Evaluasi CambridgeAdvanced (Chemistry As And A Level) Dan Kimia Kelas XI Dan XII SMA KTSP Di SMH Riau Tahun Ajaran 2015/2016

\begin{tabular}{lcccc}
\hline \multicolumn{1}{c}{ Tes } & AS Level & XI KTSP & A Level & XII KTSP \\
\hline Multiple Choice & $\sqrt{ }$ & $\sqrt{ }$ & $\sqrt{ }$ & $\sqrt{ }$ \\
Structured Questions & $\sqrt{ }$ & & $\sqrt{ }$ \\
Practical Skills & $\sqrt{ }$ & $\sqrt{ }$ \\
Planning, Analysis and Evaluation & - & \\
\hline Tabel 4. Perbandingan evaluasi Chemistry As And A Level) Dan Kimia Kelas XI/XII SMA KTSP Di \\
\multicolumn{2}{c}{ SMH Riau Tahun Ajaran 2015/2016 }
\end{tabular}

Dari tabel terlihat bahwa evalusi Cambridge advanced jauhlebih komplit dan rumit jika dibandingkan dengan KTSP. Dimana dalam chemistry As/A level siswa akan menghadapai 5 paper yakni paper 1(multiplechoice), paper 2 (As level strcture question), paper 3(practical skill), paper 4 (Alevel structured question) dan paper 5 (planning, analysis and evaluation). Sedangkan dalam KTSP hanya dikenal tes multiple choice untuk ujian akhir nasional dan ditambah soal essay untuk ujian bagi kelas nasioanal. Yang paling sulit menurut siswa adalah paper 4 yakni A level structured question kemudian diikuti oleh paper 3 (practical skill) bagi cehemistry As level 


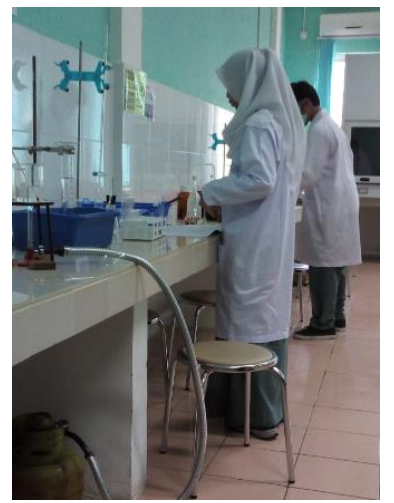

Gambar 7. Paper 3 (Practical skill) test

Salah satu yang memudahkan siswa dalam Cambridge international examination adalah tersedianya data booklet dimana disini siswa tidak dituntut untuk menghafal berbagai nilai konstanta.

\begin{tabular}{|c|c|}
\hline molar gas constant & $R=8.31 \mathrm{JK}^{-1} \mathrm{~mol}^{-1}$ \\
\hline the Faraday constant & $F=9.65 \times 10^{4} \mathrm{C} \mathrm{mol}^{-1}$ \\
\hline the Avogadro constant & $L=6.02 \times 10^{23} \mathrm{~mol}^{-1}$ \\
\hline the Planck constant & $h=6.63 \times 10^{-34} \mathrm{Js}$ \\
\hline speed of light in a vacuum & $c=3.00 \times 10^{8} \mathrm{~ms}^{-1}$ \\
\hline rest mass of proton, i ${ }_{1}^{\mathrm{H}}$ & $m_{\mathrm{p}}=1.67 \times 10^{-27} \mathrm{~kg}$ \\
\hline rest mass of neutron, idn & $m_{\mathrm{n}}=1.67 \times 10^{-27} \mathrm{~kg}$ \\
\hline rest mass of electron, $: \mathrm{e}$ & $m_{\mathrm{e}}=9.11 \times 10^{-31} \mathrm{~kg}$ \\
\hline electronic charge & $\theta=-1.60 \times 10^{-19} \mathrm{C}$ \\
\hline molar volume of gas & $\begin{array}{l}V_{\mathrm{m}}=22.4 \mathrm{dm}^{3} \mathrm{~mol}^{-1} \text { at s.t.p } \\
V_{m}=24.0 \mathrm{dm}^{3} \mathrm{~mol}^{-1} \text { under room conditions } \\
\left.\text { (where s.t.p. is expressed as } 101 \mathrm{kPa} \text {, approximately, and } 273 \mathrm{~K}\left(0^{\circ} \mathrm{C}\right)\right)\end{array}$ \\
\hline ionic product of water & $\begin{aligned} K_{\mathrm{w}}= & 1.00 \times 10^{-14} \mathrm{~mol}^{2} \mathrm{dm}^{-0} \\
& \left(\text { at } 298 \mathrm{~K}\left(25^{\circ} \mathrm{C}\right)\right)\end{aligned}$ \\
\hline specific heat capacity of water & $\begin{array}{l}=4.18 \mathrm{~kJ} \mathrm{~kg}^{-1} \mathrm{~K}^{-1} \\
\left(=4.18 \mathrm{~J} \mathrm{~g} \mathrm{~g}^{-1} \mathrm{~K}^{-1}\right)\end{array}$ \\
\hline
\end{tabular}

Gambar 8.Data Booklet for Chemistry Advanced

\section{KESIMPULAN}

Minat Siswa SMH untuk mengikuti kelas chemistry As/A level cukup tinggi di SMH. meski minat ini tidak diiringi dengan tingginya keikutsertaan dalam CIE As/A level chemistry. UntukAs level chemistry mendapat nomor urutan terbawah dari segi jumlah peminat dan urutan kedua terbawah setelah biology untuk test $A$ level dari segi jumlah peminat. Kurangnya minat siswa dalam mengikuti CIE chemistry As/A level disebabkan oleh beberapa faktor yakni: biaya, minat, kemampuan dan faktor eksternal. Chemistry As/A level benar-benar mempersiapkan siswa untuk melanjutkan ke tingkat perguruan tinggi, dimana dapat dilihat dari segi tujuan, isi, metode, dan evaluasi yang jelas, rinci, lengkap. Dimana benar benar menyeimbangkan pengetahuan, pemahaman, dan skill sehingga siswa menjadi pembelajar yang efektif dan memiliki fondasi yang kuat untuk melanjutkan pendidikan ke jenjang perguruan tinggi.

\section{DAFTAR RUJUKAN}

CIE. 2014. The curriculum with Cambridge A guide for school leaders.

CIE. 2016. Syllabus Cambridge International AS and A Level Chemistry 9701 for examination in June and November 2016, 2017 and 2018. Cambridge University Press 
Elisabeth, Monica. (2014). Implementasi Kurikulum Internasional Cambridge Dan Dampaknya Terhadap Pengelolaan Pembelajaran Biologi: Studi Kasus Di Saint John's Catholic School. Skripsi. Semarang: Universitas Negeri Semarang

Hidayat, Arif. (2011). Analisis-Komparasi Standar Kompetensi Dan Materi Sains Kurikulum Internasional Dan Ktsp Pada Rintisan Sekolah Bertaraf Internasional: Kasus Fisika Di SMP Dan SMA. Prosiding Seminar Nasional Penelitian, Pendidikan dan Penerapan MIPA. Yogyakrta: Fakultas MIPA, Universitas Negeri Yogyakarta

http://smh.sch.id/word-of-school-head/-Akses tanggal 4 April 2017

Kompri. (2014). Manajemen Pendidikan 2. Bandung: Alfabeta

Norris, rogger and ryan Lawrie. 2014. Chemistry coursebook second edition. Cambridge University Press

Teaching A2 chemistry practical skill.

Teaching AS chemistry practical skill. 